\title{
Komunikasi Transendental Antara Penari Tamborin dan Tuhan
}

\author{
Dhea Marianti, Suzy S. Azeharie \\ dheamarianti@gmail.com,suzya@fikom.untar.ac.id \\ Fakultas Ilmu Komunikasi Universitas Tarumanagara
}

\begin{abstract}
This research is the result of qualitative research discussing the communication of Tamborin dance rituals. Tamborin dance is a form of conveying the praise and worship of Christians to God. This dance is usually performed every Sunday in the worship service of the Bethel Indonesia Church in Jakarta. The purpose of this study was to find out the communication of the Tamborin dance ritual at the Great Mosque of the Bethel Indonesia Church in Jakarta. The theories used in this study are ritual communication theory, non verbal communication theory and transcendental communication theory. This study uses qualitative methods in descriptive phenomenology. Data collection techniques used by the author using interviews and observation. Data obtained from the results of in-depth interviews with six speakers. Based on the results of the study the authors found that ritual communication in Tamborin dances is Tamborin dancers can convey forms of praise, worship and thanksgiving to God through Tamborin dance which consists of five elements, namely sharing, participation, association or association, friendship and mutual belief. Transcendental communication in this study was that of the five sources the authors found that they could communicate with God through Tamborin dance.
\end{abstract}

Keywords: Communication, Ritual Communication, Non Verbal Communication, Transendental Communication Tambourine Dance

\begin{abstract}
Abstrak
Penelitian ini merupakan hasil penelitian kualitatif membahas tentang komunikasi ritual Tarian Tamborin. Tarian Tamborin merupakan suatu bentuk wujud penyampaian pujian dan penyembahan umat Kristiani kepada Tuhan. Tarian ini biasanya dilakukan pada setiap hari minggu dalam Ibadah Raya Gereja Bethel Indonesia di Jakarta. Tujuan dari penelitian ini adalah untuk mengetahui komunikasi ritual Tarian Tamborin dalam Ibadah Raya Gereja Bethel Indonesia di Jakarta. Teori yang digunakan dalam penelitian ini adalah teori komunikasi ritual, teori komunikasi non verbal dan teori komunikasi transendental. Penelitian ini menggunakan metode kualitatif secara fenomenologi deskriptif. Teknik pengumpulan data yang digunakan penulis menggunakan wawancara dan observasi. Data diperoleh dari hasil wawancara mendalam dengan enam narasumber. Berdasarkan hasil penelitian penulis menemukan bahwa komunikasi ritual dalam Tarian Tamborin adalah penari Tamborin dapat menyampaikan bentuk pujian, penyembahan dan ucapan syukur kepada Tuhan melalui Tarian Tamborin yang terdiri dari lima unsur yaitu berbagi, partisipasi, perkumpulan atau asosiasi, persahabatan dan keyakinan bersama. Komunikasi transendental dalam penelitian ini adalah dari kelima narasumber penulis menemukan bahwa mereka dapat berkomunikasi dengan Tuhan melalui tarian Tamborin.
\end{abstract}

Kata Kunci: Komunikasi, Komunikasi Ritual, Komunikasi Non Verbal, Komunikasi Transendental, Tarian Tamborin 


\section{Pendahuluan}

Gereja Bethel Indonesia merupakan Gereja Pentakosta yang menganut sistem aliran kharismatik. Kharismatik menurut Wilfred J. Samuel dalam bukunya yang berjudul Kristen Kharismatik adalah suatu teologi atau kelompok yang menyukai pengadopsian dan pelaksanaan praktek-praktek, ideologi serta prinsip yang berkaitan dengan gerakan Roh. Arti gerakan Roh menunjukan bahwa Kristus memberikan karunia-karunia rohani kepada gereja untuk membawakan perbaikan bagi dirinya melalui Roh sesuai dengan hak istimewa dan anugerah Ilahi (Samuel, 2007).

Tata ibadah aliran kharismatik memberi nilai penting pada doa pujian dan penyembahan menjadi nilai terpenting dalam gereja tersebut. Ibadah diartikan Yohanis Luni Tumanan dalam jurnalnya yang berjudul Ibadah Kontemporer: Sebuah Analisis Reflektif terhadap Hadirnya Budaya Populer dalam Gereja Masa merupakan proses membangun mezbah atau persembahan bagi Tuhan melalui doa, pujian dan penyembahan (Tumanan, 2015).

Pujian dan persembahan kepada Tuhan dapat diaplikasikan melalui tarian. menurut Bob Surge dalam tulisan Bayu Wijayanto, Lono L. Simatupang dan Victorius Ganap yang berjudul Musik Gospel sebagai Ekspresi Spiritual-Musikal Jemaat Gereja Kristen Kharismatik pujian pada Tuhan merupakan suatu tanggapan manusia sebagai tanda ucapan rasa syukur atas karya pekerjaan Tuhan Allah terhadap umat-Nya. Salah satu bentuk pernyataan pujian dalam kebaktian jemaat adalah menari (Wijayanto, et al., 2013).

Salah satu bentuk tarian dalam ibadah kharismatik adalah tarian Tamborin. Tarian ini menurut Margrate Yap dalam bukunya yang berjudul Praise Him with The Tambourine and Dance dipakai oleh umat Kristen untuk mengiringi puji-pujian pada saat berlangsungnya ibadah. Tarian Tamborin juga merupakan salah satu bentuk sarana penyampaian pujian dan penyembahan jemaat kepada Tuhan (Yap, 1990:15).

Berdasarkan latar belakang yang telah diuraikan di atas maka penulis tertarik untuk meneliti komunikasi ritual tarian Tamborin di Ibadah Raya Gereja Bethel Indonesia di Jakarta yang bertujuan untuk mengetahui komunikasi ritual tarian Tamborin di Ibadah Raya Gereja Bethel Indonesia di Jakarta.

Gambar 1. Kerangka Pemikiran

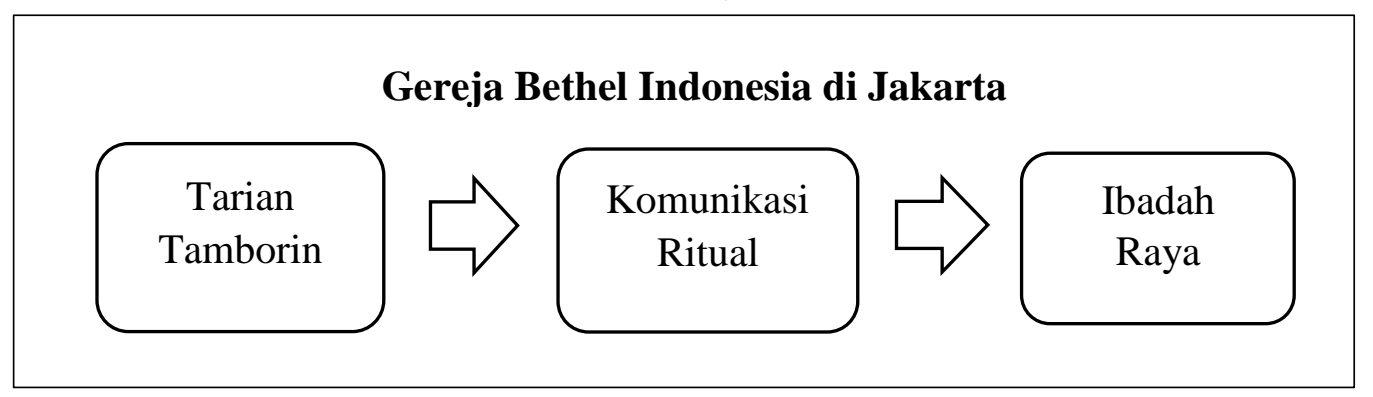

Sumber: Penulis

Gambar 1 merupakan kerangka pemikiran yang penulis gunakan dalam penelitian ini. Gambar kerangka pemikiran di atas menjelaskan komunikasi ritual Tarian Tamborin yang terjadi dalam ibadah raya Gereja Bethel Indonesia di Jakarta. 


\section{Metode Penelitian}

Dalam penelitian ini pendekatan penelitian yang dilakukan penulis menggunakan adalah pendekatan penelitian kualitatif. Metodologi kualitatif adalah prosedur penelitian yang menghasilkan data deskriptif berupa kata-kata tertulis atau lisan dari orang-orang dan perilaku yang diamati (Baswori dan Suwandi, 2008:21). Metode penelitian yang dilakukan untuk menganalisa penelitian adalah menggunakan penelitian fenomenologi. Penelitian fenomenologi merupakan anggapan umum untuk menunjuk pada pengalaman subjektif dan berbagai jenis dan tipe subjektif dari berbagai jenis dan tipe subjek yang ditemui (Moelong, 2009:14). Metode pengumpulan data yang digunakan menggunakan wawancara mendalam, observasi non-partisipan, studi kepustakaan dan pencarian data online. Menurut Baswori dan Suwandi dalam bukunya yang berjudul Memahami Penelitian Kualitatif dikatakan bahwa wawancara adalah percakapan dengan maksud tertentu oleh dua pihak yaitu pewawancara sebagai pemberi pertanyaan dan yang diwawancarai sebagai pemberi jawaban atas pertanyaan tersebut. Tujuan dari wawancara antara lain mengkonstruksi perihal orang, kejadian, kegiatan, organisasi, perasaan, motivasi, tuntutan dan memverifikasi informasi yang diterima (Baswori dan Suwandi, 2008:127). Penulis melakukan wawancara mendalam kepada keenam narasumber untuk untuk melengkapi penelitian ini. Keenam narasumber penelitian ini adalah sebagai berikut:

1. Key informan penulis yaitu Ernest (38 tahun) yang merupakan ketua komunitas Shachah di Jakarta. Komunitas Schahah merupakan komunitas Kristen yang melayani di bidang tarian termasuk tarian Tamborin. Ernest telah menari tarian Tamborin selama 20 tahun dan telah memiliki sertifikata Shachah Certified Instructors Course (SCI).

2. Yang kedua adalah Indi Kartika (29 tahun) yang bekerja sebagai Sales Supervisor di Panorama JTB Indonesia sudah dua tahun menjadi ketua departemen penari rayon Gereja Bethel Indonesia di wilayah Jakarta Barat. Selain itu ia juga dipercayakan untuk menjadi seorang koreografer tarian dalam beberapa acara di gereja.

3. Informan ketiga adalah Felita Charissa ( 24 tahun) telah menjadi ketua penari di Gereja Bethel Indonesia Tanjung Duren selama empat tahun dan telah menjadi penari Tamborin selama enam tahun.

4. Informan keempat adalah Patricia Felissa (22 tahun) yang telah menari Tamborin di Gereja Bethel Indonesia selama empat tahun.

5. Informan kelima adalah Fedora (12 tahun) yang merupakan penari Tamborin sejak sebelas bulan yang lalu.Untuk melatih kemampuannya menari fedora mengambil kursus tarian balet di Marlupi Dance Academy.

6. Informan terakhir adalah Agustinus Puspawiguna (56 tahun) yang merupakan gembala sidang serta pendeta di Gereja Bethel Indonesia Tanjung Duren, Jakarta Barat selama 20 tahun. Ia juga membuka usaha dengan membuka toko kue yang diberi nama toko Kuwe-Kuwe.

\section{Hasil Temuan dan Diskusi}

Tamborin

Menurut Margrate Yap dalam bukunya yang berjudul Bersorak-soraklah bagi Tuhan, tamborin merupakan alat yang berbentuk bundar, bulan sabit atau segi empat 
yang memiliki selaput pada satu atau kedua sisinya dengan kepingan metal yang bergemerincing seputar pinggirannya. Tamborin dimainkan dengan cara menggoyangkan atau memukulnya dengan cara yang berbeda-beda (Yap, 2016). Menurut Patricia Felissa, tamborin merupakan alat yang dipakai untuk berperang dalam roh. Salah satu sisi tamborin terdapat sisi metallic yang melambangkan peperangan di alam roh.

Makna Tarian Tamborin disampaikan oleh key informant Ernest merupakan perintah Tuhan untuk para pengikut-Nya agar menyembah dan memuji Tuhan lewat tari-tarian dan menggunakan rebana. Hal tersebut ditulis di dalam Kitab Mazmur pasal 150 ayat 4 yang menyatakan bahwa Pujilah Dia dengan rebana dan tari-tarian.

\section{Komunikasi}

Shannon dan Weaver dalam buku Hafied H. Cangara yang berjudul Pengantar Ilmu Komunikasi menyebutkan bahwa komunikasi adalah bentuk interaksi manusia yang saling mempengaruhi satu sama lainnya sengaja atau tidak sengaja. Bentuk interaksi tersebut tidak terbatas pada bahasa verbal akan tetapi juga ekspresi muka, lukisan, seni dan teknologi (Cangara, 2012). Sementara itu Bernard Berelson dan Gary A. Steiner dalam buku Wiryanto yang berjudul Pengantar Ilmu Komunikasi mengatakan komunikasi adalah tindakan atau proses transmisi informasi, gagasan, emosi, keterampilan dengan menggunakan simbol-simbol (Wiryanto, 2004).

Di pihak lain arti komunikasi menurut Richard West dan Lynn H. Turner dalam bukunya yang berjudul Pengantar Ilmu Komunikasi adalah proses sosial antara individu-individu yang menggunakan simbol-simbol untuk menciptakan dan menginterpretasikan makna dalam lingkungan mereka (West dan Turner, 2008).

Berdasarkan hasil wawancara dengan Ernest, pola gerakan dalam tarian Tamborin yang dibuat berhubungan dengan Alkitab (wawancara dengan Ernest pada tanggal 13 November 2018 pukul 14.37 WIB). Menurut Indi Kartika dalam wawancaranya menyatakan bahwa tarian Tamborin digunakan untuk meningkatkan atmosfir sukacita dalam sebuah ibadah (wawancara dengan Indi Kartika pada tanggal 6 November 2018 di Gereja Bethel Indonesia, Tanjung Duren pukul 19.00 WIB).

Felita Charissa menambahkan bahwa setiap hitungan dalam gerakan terdapat makna seperti dalam gerakan faith. Pada gerakan faith dalam hitungan 1 sampai 6 terdapat gerakan seperti simbol segitiga yang diartikan sebagai simbol Trinitas yaitu pekerjaan-pekerjaan Bapa, Putra dan Roh Kudus.

Hubungan teori dengan penelitian yang penulis lakukan adalah komunikasi merupakan tindakan atau proses transmisi informasi, gagasan, emosi, keterampilan melalui simbol seperti ekspresi muka, lukisan, seni dan teknologi. Tarian Tamborin merupakan komunikasi yang dilakukan melalui tarian dengan menggunakan alat yaitu rebana atau Tamborin untuk menghasilkan sebuah simbol yang memiliki makna atau pesan berdasarkan ayat Alkitab.

\section{Komunikasi ritual}

Menurut Deddy Mulyana dalam bukunya yang berjudul Ilmu Komunikasi mengatakan bahwa komunikasi ritual adalah komunikasi yang dilakukan secara kolektif dan erat kaitannya dengan komunikasi ekspresif. Suatu komunitas sering melakukan upacara-upacara berlainan sepanjang tahun dan sepanjang hidup yang disebut para antropolog sebagai rites of passage. Komunikasi ritual berkaitan dengan komunikasi ekspresif karena orang tersebut sedang menyatakan perasaan terdalam sebagai respons terhadap cinta, negara atau agama (Mulyana, 2010). Masih dalam 
sumber buku yang sama, dalam acara-acara tersebut orang menampilkan perilakuperilaku simbolik. Mereka yang berpartisipasi dalam bentuk komunikasi ritual tersebut menegaskan kembali komitmen orang tersebut kepada tradisi keluarga, komunitas, suku, bangsa, negara, ideologi, atau agama mereka (Mulyana, 2010).

Komunikasi ritual menurut Deddy Mulyana dapat menegaskan kembali komitmen orang tersebut terhadap agamanya. Dalam tarian Tamborin hal tersebut dilakukan secara sukarela dan membuktikan komitmen mereka kepada Tuhan lewat tarian Tamborin. Rites of passage juga terdapat dalam tarian Tamborin. Hal tersebut diperkuat oleh wawancara Patricia Felissa yang menyatakan bahwa tarian Tamborin merupakan bentuk dari cintanya dengan Tuhan.

Di tempat lain James W. Carey dalam bukunya yang berjudul Communication as Culture: Essay on Media and Society menjelaskan bahwa komunikasi ritual berkaitan dengan berbagi, partisipasi, perkumpulan atau asosiasi, persahabatan dan kepemilikan akan keyakinan iman yang sama. Komunikasi ritual adalah tindakan untuk merepresentasi atau menghadirkan kembali kepercayaan-kepercayaan bersama. Komunikasi ritual dapat diwujudkan dalam bentuk materi seperti tarian, permainan, arsitektur, kisah dan penuturan (Carey, 1992).

Berdasarkan analisis dan observasi penulis, berbagi yang dilakukan penari Tamborin adalah berbagi ilmu pada saat latihan berlangsung artinya sebelum mereka menari contohnya seperti saling mengajarkan satu sama lain cara menari Tamborin hingga gerakan tersebut menjadi sama. Partisipasi yang dilakukan penari Tamborin adalah mereka bersedia berpartisipasi dalam setiap acara gereja dan latihan tanpa dibayar sehingga partisipasi tersebut tidak dikarenakan paksaan. Perkumpulan yang dilakukan penari Tamborin adalah setiap hari Kamis mereka berkumpul bersama untuk latihan namun tidak hanya berkumpul, di luar latihan para penari juga makan bersama dan melakukan interaksi satu sama lain sehingga membangun hubungan ke arah persahabatan.

Sementara menurut Eric W. Rothenbuhler dalam tulisan Yermia Djefri Manafe yang berjudul Komunikasi Ritual pada Budaya Bertani Atoni Pah Meto di Nusa Tenggara Timor menyatakan bahwa komunikasi ritual merupakan bagian dari pemaknaan simbol. Ritual selalu identik dengan kebiasaan atau rutinitas. Ritual sebagai suatu habitual action atau aksi turun-temurun, aksi formal dan juga mengandung nilai-nilai transendental (Manafe, 2011).

Nilai transendental yang ada di Ibadah Raya yaitu suatu bentuk ucapan syukur atas penyertaan Tuhan dalam kehidupan manusia dan pengagungan kepada Allah semesta alam melalui aneka sikap, tindakan, pujian, dan penyembahan sehingga setiap pribadi merasakan hadirat Allah serta kehangatan kasih persaudaraan. Hal ini berkaitan dengan pengertian James W. Carey yang menyatakan bahwa komunikasi ritual berkaitan dengan keyakinan iman yang sama yaitu umat Kristen dapat berkumpul di Gereja Bethel Indonesia untuk beribadah di setiap hari minggu sehingga dapat menjalin kehangatan kasih persaudaraan.

\section{Komunikasi Transendental}

Hasil wawancara Ernest dengan penulis menyatakan bahwa penari Tamborin dapat berkomunikasi dengan Tuhan saat ia menari. Untuk dapat berkomunikasi dengan Tuhan harus membangun hubungan komunikasi dengan Tuhan setiap hari dan setiap waktu (wawancara dengan Ernest pada tanggal 13 November 2018 pukul 14.37 WIB). Di lain sisi Patricia Felissa menyatakan bahwa dia dapat berkomunikasi 
dengan Tuhan dan dapat merasakan Tuhan berbicara lewat hatinya saat ia menari (wawancara dengan Patricia Felissa pada tanggal 15 November 2018 pukul 21.20).

Sementara menurut Felita Charissa menyatakan bahwa tarian Tamborin merupakan bentuk dari ucapan syukur dan penyembahan seorang penari kepada Tuhan dan sudah seharusnya penari harus dapat berkomunikasi dengan Tuhan (wawancara dengan Felita Charissa pada tanggal 8 November 2018 di Gereja Bethel Indonesia Tanjung Duren pada pukul 21.27 WIB).

Indi Kartika selaku Ketua Rayon juga juga menambahkan bahwa komunikasi dengan Tuhan dapat dilakukan dengan menari dan hal tersebut dapat dilakukan ketika ia membangun hubungan dengan Tuhan (wawancara dengan Indi Kartika pada tanggal 6 November 2018 di Gereja Bethel Indonesia, Tanjung Duren pukul 19.00 WIB).

Di sisi lain wawancara Fedora dengan penulis menyatakan bahwa tarian Tamborin adalah bentuk dari persembahan penari kepada Tuhan (wawancaran dengan Fedora pada tanggal 20 November 2018 pukul 18.15).

Di tempat lain Edmund Husserl dalam buku Engkus Kuswarno yang berjudul Fenomenologi menyatakan bahwa pada komunikasi transendental terdapat perbedaan antara fakta dan esensi dalam fakta perbedaan antara yang riil maupun tidak. Oleh karena itu diperlukan penggabungan dari apa yang tampak dan apa yang ada dalam gambaran orang yang mengalaminya. Komunikasi transendental perlu dikaji bukan hanya pada ritualnya semata tetapi juga apa yang dirasakan dan dialami pada pelaku ritual. Transendental menekankan arti penting kesengajaan yaitu proses internal dalam diri manusia yang berhubungan dengan objek tertentu baik berwujud maupun tidak berwujud (Kuswarno, 2009).

Pesan yang disampaikan oleh penari Tamborin kepada Tuhan menurut Ernest adalah orang tersebut menyampaikan kebesaran, keagungan, dan kemuliaanNya Tuhan selain itu juga menyatakan sukacitaNya Tuhan kepada jemaat (wawancara dengan Ernest pada tanggal 13 November 2018 pukul 14.37 WIB).

Menurut Patricia Felisa dalam wawancaranya menyatakan bahwa pesan yang disampaikan kepada Tuhan adalah selain menyampaikan kebesaran Tuhan ia juga menunjukan rasa cintanya kepada Tuhan (wawancara dengan Patricia Felissa pada tanggal 15 November 2018 pukul 21.20).

Dari kelima narasumber penulis menghubungkan antara teori dengan penelitian penulis yang menyatakan bahwa penari Tamborin dapat berkomunikasi dengan Tuhan melalui tarian mereka dan hal tersebut dibentuk melalui kehidupan pribadinya dengan Tuhan. Hal ini memperkuat teori Deddy Mulyana yang menyatakan bahwa komunikasi manusia dengan Tuhan memang bisa dilakukan.

Teori Edmund Husserl juga menyatakan bahwa komunikasi transendental perlu dikaji bukan hanya pada ritualnya semata tetapi juga apa yang dirasakan dan dialami pada pelaku ritual. Hal ini berkaitan dengan pernyataan Patricia Felissa yang menyatakan bahwa pada saat menari ia tidak hanya sekedar menari melainkan sebelum dan selama tarian berlangsung ia menyembah dan berdoa kepada Tuhan. Para penari melakukan tarian tersebut dengan sadar. Patricia dapat merasakan Tuhan berbicara di dalam hatinya (wawancara dengan Patricia Felissa pada tanggal 15 November 2018 pukul 21.20). Hal ini diperkuat oleh pernyataan Felita Charissa yang menyatakan bahwa yang ia rasakan saat menari Tamborin adalah perasaan senang karena ia dapat menyampaikan kebaikan-kebaikan melalui doa yang ia panjatkan kemudian Tuhan berbicara dalam hatinya dan diekpresikan ke dalam tarian tersebut 
ia percaya bahwa Tuhan mendengar (wawancara dengan Felita Charissa pada tanggal 8 November 2018 di Gereja Bethel Indonesia Tanjung Duren pada pukul 21.27 WIB).

Berdasarkan hasil wawancara dan penjelasan di atas penulis merangkum bahwa seseorang dapat berkomunikasi dengan Tuhan lewat tarian Tamborin. Pesan yang disampaikan penari Tamborin adalah penari dapat menyampaikan kebesaran, keagungan Tuhan, pujian dan penyembahan serta rasa cinta mereka kepada Tuhan. Tidak hanya menyampaikan saja, namun orang tersebut juga dapat merasakan Tuhan berbicara dan merasakan sukacita saat menari Tamborin.

Sukacita yang dirasakan oleh penari Tamborin menurut Indi Kartika adalah ketika ia melihat lansia yang duduk di kursi roda dapat bernyanyi sambil bertepuk tangan dan jemaat Tuhan dapat melompat dan memuji Tuhan (wawancara dengan Indi Kartika melalui via Whatsapp pada 17 Desember 2018 pukul 14.26). Pernyataan Indi juga didukung oleh Felita Charissa yang menyatakan bahwa ia mengetahui bahwa Tuhan berbicara lewat hati saat sedang menari ia dapat merasakan sukacita, damai sejahtera dan semangat yang ia percaya bahwa asalnya dari Tuhan (wawancara dengan Felita Charissa melalui via Line pada 19 Desember 2018 pukul 00.29).

\section{Simpulan}

Tamborin merupakan sebuah alat yang berbentuk bundar pada satu atau dia sisi selaput yang memiliki kepingan metal bergemerincing di seputar pinggirannya, makna Tamborin bagi penari dipercaya sebagai senjata perang di alam roh, bentuk pujian, penyembahan serta ucapan syukur kepada Tuhan, gerakan tarian Tamborin dibuat berdasarkan ayat-ayat Alkitab sehingga setiap gerakan memiliki arti tersendiri, tarian tamborin penting dalam sebuah ibadah untuk membantu jemaat Tuhan agar ikut memuji dan menyembah Tuhan saat pujian berlangsung, komunikasi yang dilakukan melalui tarian dan gerakan dengan menggunakan alat yaitu Tamborin untuk menghasilkan sebuah simbol yang memiliki makna atau pesan berdasarkan ayat Alkitab, komunikasi ritual pada tarian Tamborin yaitu dilakukan setiap hari minggu pada saat pujian berlangsung di Ibadah Raya. Rites of passages dalam tarian Tamborin adalah respon cintanya kepada Tuhan dalam bentuk tarian, komunikasi transendental yang disampaikan penari Tamborin adalah orang tersebut dapat menyampaikan kebesaran, keagungan Tuhan, pujian penyembahan serta rasa cintanya kepada Tuhan. Penari Tamborin dapat merasakan Tuhan berbicara pada saat mereka merasakan sukacita dan damai sejahtera dalam hatinya.

\section{Ucapan Terimakasih}

Penulis berterimakasih kepada Dra. Suzy S. Azeharie, M.A., M. Phil selaku dosen pembimbing, seluruh narasumber (empat) yang telah bersedia bekerjasama selama penelitian berlangsung serta teman-teman dan keluarga yang telah memberikan dukungan dan doa kepada penulis.

\section{Daftar Pustaka}

Aldo dan Suzy Azeharie. (2018). Komunikasi Ritual pada Cermin Pa Kua. Jurnal Komunikasi Vol 1 No 1.

Basrowi \& Suwandi. (2008). Memahami Penelitian Kualitatif. Jakarta: Rineka Cipta 
Cangara, Hafied. (2012). Pengantar Ilmu Komunikasi: Pengertian Komunikasi. Jakarta: PT Grafindo Persada

Carey, James W (1992). Communication as Culture: Essays on Media and Society. Newyork: Routledge.

Manafe, Yermia Djefri. Komunikasi Ritual, Jurnal Komunikasi Vol 1 No 3, Bandung: 2011 hlm 289

Margrate Yap. (1990). Praise Him with The Tambourine and Dance. Jakarta: Christ For The Nations

Margrate Yap. (2016). Bersorak-soraklah bagi Tuhan, Jakarta: Christ For The Nations

Moelong, M. A Lexy J . (2009). Metode Penelitian Kualitatif. Bandung: PT Remaja Rosda Karya

Mulyana, Deddy. (2010). Ilmu Komunikasi : Suatu Pengantar. Bandung: Remaja Rosdakarya.

Samuel. W. J. (2007). Kristen Karismatik. Jakarta: Penerbit BPK

Tumanan. L. Yohanis, Ibadah Kontemporer, Jurnal Jaffray, Vol 13 No 1, Jakarta : 2015 hlm 42

West Richard dan Lynn H. Turner. (2008). Teori Komunikasi: Analisis Dan Aplikasi. Buku 1 (Edisi ke-3). Terjemahan Maria Natalia Damayanti Maer. Jakarta: Salemba Humanika

Wiryanto. (2004). Pengantar Ilmu Komunikasi. Jakarta: PT Gramedia Widasarana Indonesia 